\title{
Lapurdum
}

LAPURDUM Euskal ikerketen aldizkaria | Revue d'études basques |

Revista de estudios vascos | Basque studies review

$9 \mid 2004$

Numéro IX

\section{Salvat Monho olerkariaren metrika}

Jean Haritschelhar

URL : http://journals.openedition.org/lapurdum/829

DOI : 10.4000/lapurdum.829

ISSN : 1965-0655

Éditeur

IKER

Édition imprimée

Date de publication : 1 novembre 2004

Pagination : 135-147

ISBN : 2-68781-376-X

ISSN : $1273-3830$

\section{Référence électronique}

Jean Haritschelhar, «Salvat Monho olerkariaren metrika », Lapurdum [Linean], 9 | 2004, Sarean emana----an 01 mars 2009, kontsultatu 25 avril 2019. URL : http://journals.openedition.org/ lapurdum/829 ; DOI : 10.4000/lapurdum.829 


\title{
Salvat Monho olerkariaren metrika
}

\author{
Jean HARITSCHELHAR \\ Michel de Montaigne Bordeaux 3 Unibertsitatea \\ Euskaltzainburua \\ IKER 5438 CNRS
}

Duela hogeita hamar urte baino gehiago Ikas batasuneko zuzendaritzak erabaki zuen argitaratzea Piarres Lafitte euskaltzainak egina zuen liburua Salvat Monho (1749-1821) olerkariaren kantuak biltzen zituela osoki esku-idazki bati esker. 1972an agertu zen liburua Poèmes basques de Salvat Monho (1749-1821), présentés, transcrits, traduits et a nnotés par Pierre Lafitte de l'Académie Basque, Editions Ikas, Musée Basque, rue Marengo, 64-Bayonne, 1972.

Orotarat, 51 kantu dira, 16 profanoak eta 35 elizako kantikak. Gutitan, euskal literaturan, aurkitzen dira hainbeste kantu idazle bakar batek eginak eta obra oso horretaz baliatuko naiz Salvat Monho olerkariaren metrikaren aztertzeko.

Salvat Monho Izturitzen sortu zen 1749an eta gazte zelarik umezurtz gelditu zen, zortzi urte zituela bakarrik. Asma daiteke aski gazte sartu zela Larresoroko seminario berrian, berrikitan eraikia baitzuen Daguerre apezak. Dakiguna da apeztua izan zela 1774 ean, hogeita bost urte zituela.

XVIII. mendeko apez horietarik da Salvat Monho, gizon ikasia, latina eta frantsesa jakinki behar den bezala, bi hizkuntza horiek baliatuak baitziren bereziki orduko erakaskuntzan.

Bada Frantzian hezkuntzari buruz kezka haundi bat. Fénelon artzapezpikuak idazten du Traité de l'éducation des filles, beraz nesken irakaskuntzarako gidaliburua, eta geroxago, izendatu zutelarik Luis XIV.-ren bilobaren erakasle, harentzat idatzi zuen Les a ventures de Téléma que. XVIII. mendearen bigarren zatian Jean-Jacques Rousseau-k idazten du L'Emile, eleberri pedagogikoa (1762), nahiz ez zituen azaltzen zituen ideiak aplikatu bere haurrei. Argien mendean gaudelarik ikus daiteke kezka berbera agertzen dela Euskal Herrian, lekuko dela Sarako Etxeberriren liburua : Escual Herri eta Escualdun guztiei escuarazco hatsapenac la tin ica steco eta, apezen hobeki moldatzeko, Larresoroko seminarioaren idekitzea.

Gizon ikasia zela Salvat Monho, ez da dudarik ; Bacchus-i eskaintzen dio kantu bat oso alegera, zinez ostatuko kantua, arnoaren gozoa goraipatzen duena, tristuraren kasatzeko erremedio ona :

Dugun edan berriz ere; beti dut aditzea, Bien ondotik on dela hirugarren kolpea; Oraino triste badire gure bihotz barrenak Alegera tuko ditu menturaz la ugarrenak. 
"Poeten errenkurak Apolonen kontra" deritzan kantuan adiarazten du gaizki bizi direla olerkariak :

Parnasean dabiltzanen sabelak eta moltsak

Airez hantzen ez badire, ardura dire hutsak.

eta hortakotz agertzen ditu bere kezkak. Bi etsenplu horiekin ikus daiteke nor zen Salvat Monho.

Azkaingo menetei ihardesten dielarik hiru gizon sakratu dituztelakotz koplatu, bera barne, argi eta garbi erakusten du haren kontra agertu diren jorraldiak eta gezurrak, haien artean "sobera dakiela", "ederki mintzo dela".

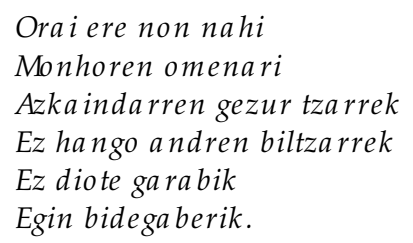

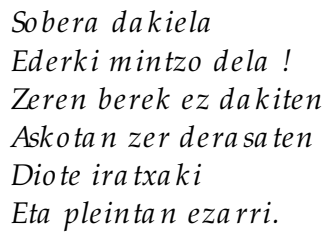

Apez ikasia beraz, Salvat Monho-k bi aurpegi agertzen ditu. Kantikak idatziz erakusten du eliza gizon zintzoa dela, doktrina behar den bezala azalduz, bainan denbora berean ezagutu du frantses iraultza, haren kontra jokatu da zin egileen aurka, sortuz kantu garratzak noiztenka, umorez beteak askotan. Zinez XVIII. mendeko olerkari bat da, bere garaian murgildua, kantua baliatuz bere ideien barreiatzeko, kantuak baitzuen, bereziki Frantzian, eragin haundi bat.

\section{Ohidurari jarraikiz}

Ohidura zahar bat badago Euskal Herrian, bertsulariena bereziki, kantuak sortzen direla aire ezagun zahar bat segituz. Ez dute besterik aitortzen kantu-egileek derasatelarik :

Ahaire zahar huntan bi bertset berririk.

(Arengaraiko primaren khantorea)

Mendiague batek ere idazten du :

Airea zahar eta kantorea berri

Sujetak ere dire anhitz xarmagarri.

"Arbasoak" deritzan olerkian hauxe dio Elizanburu Saratar koplari famatuak:

Mila bat zortzi ehun eta la uetan hogoiean

Bertsu berri hauk eman dire aire zahar batean.

Ohidura zaharrari jarraiki zaio Salvat Monho zazpi kantutan, bereziki kantu profanoetan sei direlarik. Horiek dira :

- Chanson bachique (4 bertsu),

- Urruña ko Jaun erretorari (15 bertsu),

- Ga ra teta Iturbiderentzat (12 bertsu),

- Iha rdestea ( 8 bertsu),

- Garat-ek Erregeri hiltzeko arrasta irakurtu ondoan (bertsu bakarrekoa),

- Poeten errenkurak Apolon-en kontra (8 bertsu).

Kantu horietan lau neurtitzeko bertsua baliatzen du, neurtitz bakoitzak 15 silaba dauzkala, bi zatitan emana $8+7$, eten batekin zortzigarren silabaren ondotik. 
Aspaldian ezagutuak dira bai bertsuak eta bai neurtitzak euskal literaturan Etxeparerekin hasi-eta, segitzen dutela XVII. mendean Etxeberri Ziburukoak, Harismendi-k, Hirigoity-k, Argainaratz-ek.

Egia da ere $8+7$ neurtitzak hatzematen ditugula Hegoaldeko kantu zahar batean : Mila urte igarota ura bere bidean; Gipuzkoarrak sartu dira Gazteluko etxean, Nafarrokin batu dira Beotibarren pelean.

Etxepareren neurtitzez Oihenart-ek zion ez zirela holakorik aurkitzen beste literaturetan: "Ce sont tous de Vers de quinze syllabes, dont nous ne trouverons point dexemple parmy les ouvrages des poètes fra nçois, Ita liens et Espaignols (ches lesquels Les plus longs Vers sont les a lexandrins féminins contenant treize syllabes) et parmy les Latins Encore moins (Gure Herria, 1967, 227-228 or.) “.

Hamahiru silabako neurtitza aurki daiteke ere Salvat Monho-ren "Erregeren otoitza" deritzan kantuan lau neurtitzeko bertsuetan, etena delarik zazpigarren silabaren ondotik $(7+6)$.

Lau neurtitzeko bertsuari buruz bi ohar :

1. Gehienik Monho-k erabiltzen duen bertsua da lauko ertaina $(8+7)$, sei aldiz, eta aldi bat bakarrik lauko ttipia $(7+6)$. Ez du sekulan erabiltzen lauko nagusia $(10+8)$, hain erabilia izanen delarik XIX. eta XX. mendeetan.

2. Ez du bertsularien ohidura segitzen errima berbera erabiliz lau neurtitzetan. Frantses modura doa bi errima parekatuak ( $\mathrm{a}$ a b b) baliatuz, salbu "Ihardestea" deitzen den azken bertsuan :

$$
\begin{aligned}
& \text { Idalgotan sartu gabe direla sinetsiak } \\
& \text { Gure osebak direla edo gure kusiak, } \\
& \text { Deputatu egin tugun Garat a naia biak } \\
& \text { Ardiesten badituzte gure galde guziak. }
\end{aligned}
$$

Hori da salbuespen bakarra.

Ez da lehena hola jokatzen dena. Bada, XVII. mendetik hasiz, holako ohidura Iparraldeko euskal idazleetan, hain zuzen, jadanik aipatu ditudan olerkariek finkatua, Etxeberri Ziburukoak, Harismendi-k, Hirigoity-k. Horretan datza ene ustez bertsolaritzaren eta olerkigintzaren diferentziarik nabarmenena, olerkariek frantses metrika dutela eredutzat hartzen. Argi dago bi ohidura desberdin aurkitzen direla : alde batetik neurtitz luzearen erabilera izan dadien $(8+7)$-koa edo $(7+6)$-koa, bainan errima parekatuekin eta ez errima bakarra baliatuz.

\section{Sorkuntza berria}

Kantua kantu, aireak edo doñuak manatzen du. Aspaldiko ohidura da "Aire zahar batean bertsu berriak" paratzea eta ez du besterik egin Salvat Monho-k, ez baitu, dakidanez, aire berririk sortu. Askotan, bainan ez beti, aitortzen du berak zein aire baliatu duen kantu baten emaiteko. Hain zuzen, interesgarria da jakitea zein diren, beraz, nola sortu den kantua.

Hamazazpi kantu eginak dira frantses aire bat baliatuz, bainan orotara hamar airetan : 
1. De to ut un peu (lau aldiz),

2. Ah! vous dirai-je maman,

3. Dans cette étable (hiru aldiz),

4. La marche du régiment $d u$ Perche (bi aldiz),

5. Il fa ut a ttendre avec patience,

6. Je viens à vous Seigneur: instruisez-moi,

7. Foudres, éclairs, trompette et tonnerre (bi aldiz),

8. Avec les jeux dans le village,

9. Tout n'est que va nité,

10. Vive Jésus, vive sa croix.

Latin kantuetarik bi aire :

- La uda Sion,

- Te Deum la udamus.

Aire euskalduna baliatuz egin ditu hamar kantu zortzi aire direla bakarrik :

1. Beltzuntzeren koplen airean (bi aldiz),

2. Atzar gaiten atzar lotarik,

3. Amodiorik baduzula ez ziautazu iduri,

4. Lauda zagun misterio handia,

5. Joan zaut loa, joan zaut jana (bi aldiz),

6. Pelegrinen airean,

7. Dezagun kanta gogotik,

8. Zerutik jautsi ziren bitima garbia.

Aire horietan dudatan ezartzen ditut bi aire bederen : "Beltzuntzeren koplen aire" delakoa, kopla horiek beste aire batean eginak izan daitezkeelakotz eta "Atzar gaiten atzar lotarik" eguberriko kantu ezaguna, Etxeberri Ziburukoarena, oraindik kantatzen dena $(9+8)$ duen egituraren gatik. Hirugarren bat izan daiteke "Pelegrinen airea", hau ere (9-4-9-4-8-5-8-7) duen egituraren gatik, aspaldian ezagutuak baitira frantses pelegrinen kantuak, hala nola Troyes hiriko bilduman. Adibidez :

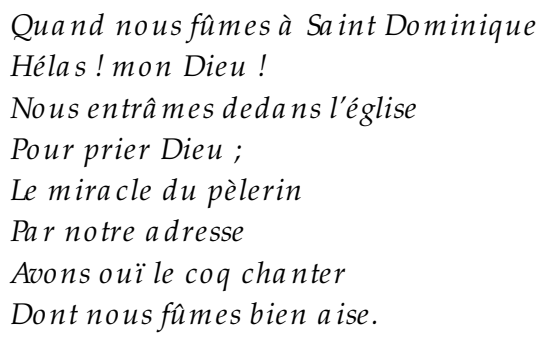

Orotara 29 kantu dira aire ezagutu batean kantatzen direnak, 20 direlarik aire horiek. Gelditzen dira 22 kantu aire ez ezagutu batekin kantatuak, haien artean lauko ertaineko sei kantuak, aire euskaldun batean asma daiteken bezala eta lauko ttipikoa.

Halere nabaria da frantses doñuen eragina eta horrek ondorioak baditu kantuen egituran. Azter ditzagun bertsu bakoitzean nola uztartzen diren neurtitzak. 


\section{Hiru neurtitzeko bertsua}

"Lauda Sion" deitzen den kantuan agertzen da bertsu hau : 18 bertsu dira 8-8-7 egiturarekin laukoa agertzen dela $8-8-8-7$ lau bertsutan eta bostekoa $8-8-8-8-7$ azken bi bertsuetan. Egia erran Salvat Monho-k segitzen du latinezko kantua, bai hitzetan eta bai metrikan. Alabainan parekatzen dira bertsuak lehen 18etan a a b c c b d d e f f e eredua segituz.

Sion, Salbatzaile ona,

Gidari eta artzaina,

La uda zazu kobletan

Ez gupidets ein a ha la

Zeren ezin a ski la uda

Baidaiteke sekulan.

Laukoa hasten da "Fracto demum sacramento" latinez, "Ostia hautsirik ere" euskaraz a a b b ereduarekin.

Ostia ha utsirik ere,

Ez dudan egon batere

Hanbat dela zatittoan

Nola baida osoan.

Azken bi bertsuak hasten dira "Bone pastor panis vere" hitzekin, "Jesus artzain Jesus ogi" euskaraz a a b b a egiturarekin.
Guziz zuhur, boteretsu,
Zuk hemen hazten gaitutzu:
Hor ere, mahain berean
Zure sainduen artean
Otoi plaza gaitzazu

\section{Lau neurtitzeko bertsuak}

Jadanik ikusia dugu lauko ohikoa, errima bakarrekilakoa. Beste mota batzu agertzen dira Monho-ren olerkietan. "Eskandala" deritzana, Mentaberri apez zinegilearen kontra egina da bederatzi eta zortzi silabako neurtitzekin (9-8-9-8) errima gurutzatuekin ( $\mathrm{a} b \mathrm{a}$ b). Lehenbiziko bertsua errepikatzen da eta bosgarren bertsuraino errepikatzen da eta gero beti "Eskanda la izigarria"-rekin hasiz, aldatuz badoa, errepika gisa gelditzen delarik, egitura bera atxikiz (9-8-9-8) eta (a b a b). Airea : "Atzar gaiten atzar lotarik" ongi hautatua da Bardozeko jendeen atzarrazteko, ikus dezaten zer diren apez zinegileak Mentaberry eta Tisso.

\author{
Orai artean Bardoztarrek \\ Lege bat zuten segitzen. \\ Bainan orai Ja inkotiarrek \\ Bertzela dute pentsatzen.
}

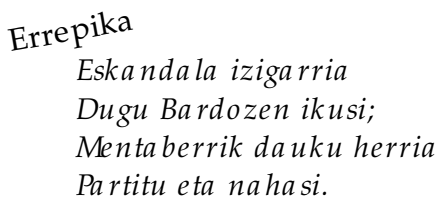

"Jaunaren hitzaz" deritzana beste gisara egina da. Egitura (8-9-8-9) errima gurutzatuekin ( $\mathrm{a}$ b a b). Errepika bat dauka, zortzi silabako bi neurtitzeko errima parekatuekin $(\mathrm{c}-\mathrm{c})$. 
Laster eigun predikura:

Jauna da han mintzo zaikuna

Eta haren gantzudura

Bihotzak hunkitzen tuena.

Errepika

Laster eigun predikura,

Graziaren ur-burura.

Errepikaduna ere "Ifernuaz eta hango penaz" neurtitzak direlarik zortzi eta zazpi silabakoak (8-7-8-7) errima gurutzatuekin (a b a b) errepikak eskaintzen dituelarik bi neurtitz errima berarekin, sei eta zazpi silabadunak (6-7) eta (c - c).

Kreatura da mnatua,

Hire penak zer diren,

Zer den hire infernua

Zenbat dukan sofritzen.

Errepika
Erraguk, erraguk
Argitu nahi gaituk

Bi kantutan hautatuko ditu beste neurtitz batzu, hamaika eta hamar silabakoak, aldizkatuz neurtitzak : "Purgatorioaz" delakoan (11-10-11-10) beti errima gurutzatuekin ( $\mathrm{a} b \mathrm{a} b)$.

O a rima Ja inkoaz onetsia,

Orroit hadi badela leku bat

Hemen arras Jaunaren justizia

Sa tifa tu ez duenarentzat.

"Predikua hasterakoan" aldiz (10-11-10-11) atxikiz errima gurutzatuak (a b a b).

Otoi, Ja una zuk argi gaitzazu,

Zuk bakarrik zure lege saindua

Progotxoski irakasten duzu

Bihotzetan ezartzen finkatua.

Beste bi kantuk egitura berezi bat daukate. "Azken jujamenduak" eta "Te Deum la udamus" deritzanak eginak dira baliatuz hiru neurtitz ezberdinak (11-10-11-8) errimak gurutzatzen direlarik ( $a b$ b $)$.

$\begin{array}{ll}\text { Aditzen da tronpeta lazgarria, } & \text { Egun, Jauna, gure bozkarioak } \\ \text { Etorri da Jaunaren eguna } & \text { Galdetzen tu leku guzietan } \\ \text { Egun triste, egun lotsagarria } & \text { Kanta diten zure laudorioak } \\ \text { Eta egun handiena } & \text { Himno eta kantiketan. } \\ \text { (Azken jujamendua) } & \text { (Te Deum laudamus) }\end{array}$

Beste mota bat eskaintzen du Salvat Monho-k "Jondoni Joani Batistaren la udoriota n" deitzen den kantuan nahasten dituelarik hamaika silabako neurtitzak bostekoarekin (11-11-11-5) errima gurutzatuak baliatuz.

Mundu galdu hau erreparatzeko,

Kristo lurrerat etorri zaizkigu.

Egun Batista ongi la udatzeko

Garbi gaitzazu. 


\title{
3. Bost neurtitzeko bertsua
}

Kantu batetan bakarrik agertzen da bost neurtitzeko bertsua. "Ave Maria" delakoan nahasten ditu hamaika eta hamabi silabako neurtitzak bertsua bukatzen delarik sei silabako neurtitz batekin aurreko neurtitzaren bigarren zatia errepikatuz (11-11-12-12-6), bainan kantu honetan errima parekatuak eskaintzen ditu (a a b b b). Adibidez :
Bete zaitu Jaunak bere graziaz, Zurekin da izaitez, zuhurtziaz, Emazten artean benedikatua Zare, eta Jesus zuk eman fruitua Zuk eman fruitua.

\section{Sei neurtitzeko bertsuak}

Lau aldiz baliatzen du sei neurtitzeko bertsua. "Azka ingo menetei" eskaintzen dien kantuan zazpi eta zortzi silabako neurtitzak agertzen dira (7-7-8-8-7-7) eta ikusiz nola lerrokatzen diren errima parekatuez ornituak dira, beraz ( $a$ a b b c c).

\author{
Hirur gizon sakratu \\ Ahal tuzte koplatu \\ Zenbait meneta ausartek \\ Edo debot hipokritek \\ Uztaila ren bieko \\ Birjina a rarteko.
}

"Bekatorearen zortea" azaltzen duelarik lau neurtitz mota baliatzen ditu : zortzi, bost, lau eta zazpi silabakoak (8-5-8-4-8-7) errima parekatua lehen bi neurtitzetan, gurutzatua beste lauetan ( $\mathrm{a}$ a a b a b).
$O$ zein den zorte tristea,
Bekatorea,
O zein den zorte tristea
Pentsa-zak maiz
Bekatuan bizitzea
Salbatu nahi bahaiz.

Beste biek "Dohatsu egiazkoak" eta "Ja inkoaren presentziaz" egitura bera daukate zortzi eta bederatzi silabako neurtitzen (8-9-8-9-8-8) errima gurutzatu eta parekatuez eginak ( $\mathrm{b}$ b a b c c)
Munduak aberatsenak Dagoka direla dohatsu;
Abrahami Ja unak berak
Ordean bertzela Jaunak Abisu hau eman zioen,
Mendian erakatsi dauku: Egin zitzan bere obrak Izpirituz pobre dena Perfet izan nahi bazuen
Erran du dohatsu dela. Haren obedientzian (Dohatsu egiazkoak)
Eta haren presentzian.
(Jainkoaren presentziaz)

\section{Zazpi neurtitzeko bertsuak}

Orotara zortzi kantu oso desberdinak doñuaren arabera eginak baitira. Hiru multzotan bil daitezke. 
a) "Erromako gortetik" eta "Mentaberriren posesionetan sartzearen okasionea" eginak dira "Beltzuntzeren koplen" airean eta beraz egitura berbera daukate 7-7-67-7-6-6 aldizkatzen direlarik zazpi eta sei silabako neurtitzak errimak parekatuekin a $\mathrm{a} b \mathrm{c} \mathrm{c} \mathrm{b} \mathrm{b.}$

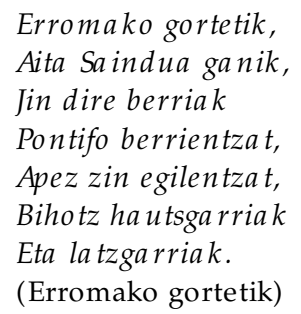

\author{
Gure eliza hartu \\ Eta handik kasatu \\ Gaitu Mentaberrik, \\ Etsaiek zitadela \\ Hartzen duten bezala, \\ Tropak ezarririk \\ Alde orotarik. \\ (Mentaberriren posesionetan...)
}

b) Lau kantu, biga profanoak "Bardozen glub" eta "Distrikerat" eta biga elizakoak "Usa ia ko a ktak" eta "O Betleem" oraindik kantatua den eguberriko kantua, horiek guziak frantses aire bat "De tout un peu" segituz. Bainan ez dute egitura berbera ukanen. Iraultza denborakoak, lehenbiziko biak, berdinak dira lau, bederatzi eta zortziko neurtitzak nahasiz. (4-9-4-8-9-9-4) bertsu bakoitzean lau silabako neurtitza errepikatzen dela hiru aldiz errimak kurioski banatuz. a b a a b b a, errima besarkatuak agertzen direlarik azken lau neurtitzetan.

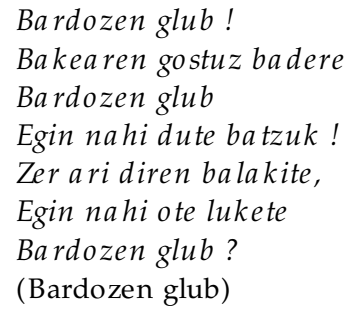

\author{
Distrikerat! \\ Lehen gizonak joan badire \\ Distrikerat \\ Apezen akusatzerat, \\ Zenbait dontzeila izan ere \\ Bardozetik joan omen dire \\ Distrikerat. \\ (Distrikerat)
}

Egitura bera dauka "O Betleem"-ek neurtitzetan eta errimetan, berezitasun batzu aurki daitezkelarik "Usaiako aktak" kantuaren errimetan. Alabainan lehenbiziko bertsuan aurkitzen dugu a b a b c c a, bigarrenean aldiz a b a a b b a, bertze hiru kantuetan bezala.

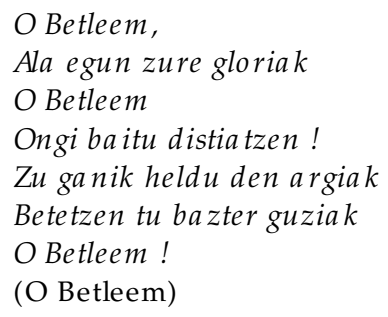

Sinesten $d u t$

Elizak dagozkan egiak

Sinesten $d u t$

Ha la direla guziak.

Neronek ikusirik baino

Hark erranik segurkiago.

Sinesten dut.

\author{
Ja una baitan \\ Eman dut ene fidantzia \\ Jauna baitan, \\ Haren miserikordian \\ Ediren uste dut bizia \\ Eta salba tzeko grazia \\ Jauna baitan \\ (Usaiako aktak)
}

c) Azken multzoan daude elizako bi kantu "Justuaren fidantzia umilla" eta "Birjina sainduaren kantika", biak kantatzen direla "Joan zaut loa, joan zaut jana"ren airean. Egitura bera beraz zortzi eta zazpi silabako neurtitzekin (8-7-8-7-8-8-7) errimak direlarik ( $a b a b c c b)$. 


$\begin{array}{ll}\text { Berant zaitutezagutu } & \text { Ez dezaket sekretuan } \\ \text { O Jesus dibinoa; } & \text { Iduk ene gozoa: } \\ \text { Berantegi dut senditu } & \text { Erantzun bedi munduan } \\ \text { Zure amodioa; } & \text { Ene bozkarioa. } \\ \text { Zure karitateari } & \text { Mundu guziak behardu } \\ \text { Berant diotihardetsi. } & \text { Ene baitan adoratu } \\ \text { Hau da ondikoa! } & \text { Jainko egiazkoa. } \\ \text { (Justuaren fidantzia umilla) } & \text { (Birjina sainduaren kantika) }\end{array}$

\section{Zortzi neurtitzeko bertsuak (zortzikoak)}

Zortziko hauetan neurtitz bakoitzak dauka bere errima, beraz egiazko zortzikoa da eta ez Hegoaldean deitzen dena.

Orotara 11 kantu dira, denek errimetan eskaintzen dituztela egitura berbera erran nahi baita errima gurutzatuak ( $\mathrm{a} b \mathrm{a} b \mathrm{c} d \mathrm{c}$ d). Egia da bertsu batzutan, bainan gutitan agertzen dela beste egitura bat ( $\mathrm{a} b \mathrm{a} b$ a $\mathrm{b}$ a $\mathrm{b})$.

Zortzi eta zazpi silabako neurtitzez eginak dira haien artean zortzi kantu (8-7-8-78-7-8-7), bat profanoa: "San Kasteteneko andregaiak Filipineko oilarrari" eta beste zazpiak elizakoak: "Apostoluen sinbola edo Credoa", "Bertute teologalak", "Bertute moralak", "Relisionaren bertuteaz", "Gizonaren azken finak", "Denboraren balioa" eta "Umilita tea".

I. Oilar kruel, oilar bortiz

Ooilar fanfarruna!

Gure oiloak bi aldiz

Alargundu tuana,

Goregi kantatzen baduk

Ereman bitoria,

Promes da uat, galduko duk

Laster hire bizia!

(San Kasteteneko andregaiak...)

II. Sinesten dut Ja inko Aita

Guziz boteretsuan :

Guzien egilea da

Lurrean bai zeruan.

Ikusten diren guziak

Berak ditu kreatu

Eta ezin ikusiak

Iza itea $z$ dohatu (bis)

(Apostoluen sinbola edo Credoa)

III. Munduko jakintsunak

Eta haren argiak

Ma iz tronpatzen tu gizonak,

Lilluratzen begiak.

Bainan fedea gidari

Hartzen duen guziak

Ikusten ditu segurki

Jakin behar egiak.

(Bertute teologalak)
IV. Fedea z giristinoa

Dohatu duenean,

Ezarri dio koroa

Jaunak buru gainean.

Bainan beti orroit bedi

Na usi bat baduela

Bizi ez bada zuzenki

Punituko duena.

(Bertute moralak)

V. Gure kreatza ileari

Adorazionea

Haren handiatasunari

Zor zaion ohorea

Bihurtzerat erakartzen

Gaituen bertutea,

Bertute hortan zerratzen

Da relisionea

(Relisionaren bertuteaz)

VI. Herioak mundu huntan

Ez du nihor gupida :

Monarken palaziotan

Etxoletan bezala

Sartzen da berdin a usartki

Eta haren kolpeak

Badaramatza sotilki

Zahar eta gazteak.

(Gizonaren azken finak) 
VII. Denboraren balioa

Ez daiteke estima.

Zerua da prezioa

Ixtant ba kotxarena.

Hartaz ongi baliatuz

Heltzen dire zerurat,

Hura gaizki enplegatuz

Betikotz infernurat

(Denboraren balioa)
VII. O umilita te sa indu, Bertuten zimendua, Sa induta sunak zu zaitu Betiko sustengua. Zenbatenaz a pa lago Bai datza ezarria Hanbatenaz bortitzago Da zimendu berria . (Umilitatea)

Argi dago $(8+7)$ neurtitz luzea zatitzen dela bi neurtitzetan, bakoitza errimadun izanez. Sendi daiteke zein maite zuen Salvat Monho-k 8 eta 7 silabako erritmoa edo luzea edo zatitua.

"Zerurako hats-gorapenak" deitua "Pelegrinen airean" sortua da. Jadanik aipatua dut frantses doñuak azaltzen nituelarik. Egitura : (9-4-9-4-8-5-8-7).

Zeruan da ene herria:

Beher huntan

Biderant bat naiz etorria

Egun hautan.

Munduko distiadurak

Ez nau xoratzen;

Zorionaren itxurak

Ez deus ditut kondatzen.

Gelditzen dira "Hirur izen sainduan : Jesus, Maria, Josepen inbokazioneaz" (7-6-76-7-6-7-6) lauko ttipia zortzi neurtitzetan jarriz eta "Baketiarren eta mendekarien artean ihardukia", hau egituratzen dela (9-8-9-8-9-8-9-8). Dakigularik azken honek airea daukala "Avec les jeux dans le village", argi eta garbi dago frantses kantua zortzi silabakoa dela aldizkatuz errima femeninoak eta errima maskulinoak, edo gazteleraz llano/agudo. Hola sortu dira gure $(7+6),(8+7)$ et $(9+8)$.

$$
\begin{aligned}
& \text { Jesus, Maria, Josep, } \\
& \text { Beti behar tugu } \\
& \text { Benera tu krista uek } \\
& \text { Eta maiz a ipatu. } \\
& \text { Mihiz eta bihotzez } \\
& \text { Aipa tuz a rdura, } \\
& \text { Izen horien bidez } \\
& \text { Heltzeko zerura. } \\
& \text { (Hirur izen sainduen...) }
\end{aligned}
$$

Gaizki a diturik legea, Juduek uste bazuten Adixkideen maitatzea Zela xoilki manatzen, Lege-emaile dibinoa Garbiki da esplikatu: Egiazko a modioa Etsai berentzat manatu. (Baketiarren eta mendekariaren...)

\title{
7. Bederatzi neurtitzeko bertsuak
}

Bederatzi kantuk osatzen dute sail hau. "Madama Beltzunzeri" eskainitako kantuak egitura berezia dauka nahasiz bederatzi, zortzi eta lau silabako neurtitzak : (9-8-9-8-4-4-9-8-8) errimak banatuz (a b a b c c b d d) ereduan, nahasiz errima gurutzatuak eta errima parekatuak. Holakorik ez da hanitz ikusten euskal literaturan.

\author{
Eskual herrien edergailu \\ Parisetik etorria, \\ Zer inkontru gaixtoz da ukuzu
}




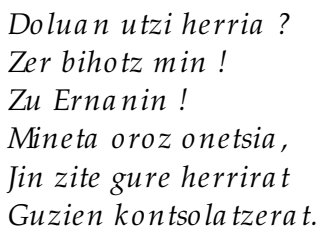

"Dans cette étable" doñuarekin hiru kantu dauzkagu, bat profanoa "Nafar goxoan", beste biak elizakoak "Justuen bozkarioak" eta "Aingeruez" (5-6-5-6-6-6-7-6$5)$ egiturarekin bertsu bakoitzean eta hori hiru kantuetan lehen eta bederatzigarren neurtitzak berdinak direla, bukaerak errepikatzen duela hasiera. Errimak gurutzatuak lehenik, parekatuak gero eta azkena lehen bezalakoa ( $\mathrm{b}$ a b c c d d a).

$\begin{array}{lll}\text { Nafar goxoan } & \text { Hain da eztia } & \text { Aingeru tropak } \\ \text { Trenpatuz bixkotxak } & \text { Jaunaren legea, } & \text { Zituen kreatu } \\ \text { Hartu ondoan } & \text { Barne guzia } & \text { Jaungoiko onak } \\ \text { Altxaturik bozak } & \text { Uzten du betea } & \text { Eta destinatu } \\ \text { Erragun bertsuta } & \text { Esperantza one } & \text { Gure gidatzeko } \\ \text { Kurruxa, plan, plan, plan } & \text { Kontsolazionez. } & \text { Eta beiratzeko } \\ \text { Gurexangrin guziak } & \text { Ene gustu handia } & \text { Zerurako bidean } \\ \text { Diren ehortziak } & \text { Han dutezarria } & \text { Etsaien artean } \\ \text { Nafar goxoan. } & \text { Hain da eztia. } & \text { Aingeru tropak. } \\ \text { (Nafar goxoan) } & \text { (Justuen bozkorioak) } & \text { (Aingeruez) }\end{array}$

Azken multzo batean sar daitezke bost kantu, "Orroitzapenak", airea "Sur la marche du régiment du Perche", kantu profanoa eta bertzeak elizakoak, "Bekatu mortala", "Bekatu beniala", "Bekatu kapitalak" eta "Sa kramenduak", denak egitura berekoak : (9-8-9-8-8-8-8-8-7), kantu profanoan errimak banatzen direla (a b a b a c c c a), elizakoetan aldiz ( $\mathrm{b}$ a b a c c c b), azken errima bakarrik aldatzen dela.

$\begin{array}{ll}\text { I. Mundu hunen hastapenetik } & \text { III. Jainkoa maite duenari } \\ \text { Gure egunetaraino } & \text { Hutsik xumenak min d } \\ \text { Kain infamearen ganik } & \text { Aitetan den hoberenari } \\ \text { Ez da jautsi Pinet baino } & \text { Damu egiten baitio; } \\ \text { Munstro itsusiagorik, } & \text { Eroriden bezain sarri } \\ \text { Robespierre eta Jourdan } & \text { Altxatzerat du egiten, } \\ \text { Gizonen etsaiez landan } & \text { Nigar karatsak ixurtzen } \\ \text { Ez Frantzian, ez Europan } & \text { Penitentzian bilatzen } \\ \text { Hain fama gaixtoagorik. } & \text { Zenbait erremedio. } \\ \text { (Orroitzapenak) } & \text { (Bekatu beniala) } \\ & \\ \text { II. Bekatua, mustro lazgarri } & \text { IV. Orroit hadi urgullutsua } \\ \text { Gure arimen etsaia, } & \text { Ixtil puxka bathaizela } \\ \text { Hire ondotik duk etorri } & \text { Lizunkeriaz orhatua } \\ \text { Herioaren premia! } & \text { Hil bezain sarri ustela. } \\ \text { Hik duk munduratekarri } & \text { Bizian adimendua } \\ \text { Arimen etsimendua } & \text { Ilunbezduk estalia, } \\ \text { Izurriaren kotsua, } & \text { Eta hi haizen guzia } \\ \text { Aire hain korronpitua, } & \text { Ez deusetarik hasia, } \\ \text { Gaitz guzien ibaia! } & \text { Amets baten itzala! } \\ \text { (Bekatu mortala) } & \text { (Bekatu kapitalak) }\end{array}$

V. Soldadoaren lantzak dautzu Jesus, sahetsa ideki: Zauri sakratu horrek ditu Gure minak sendarazi. Zauri hortan zaizko sortu Sakramenduen grazia, Biziaren iturria, Zorionaren bahia Gizonen arrazari. (Sakramenduak) 


\section{Hamar neurtitzeko bertsuak}

Bi kantu, biak elizakoak. "Ja una ren otoitza" deitzen da lehena, zortzi, zazpi eta sei silabako neurtizez egina : (8-8-8-8-7-7-6-6-6-6) gero eta ttipiagoak direla neurtitzak simetria zainduz : 4-2-4 ; bai neurtitzetan eta bai errimetan (a b a b c c d e d e) gurutzatuak lehenik, parekatuak gero eta gurutzatuak azkenik.

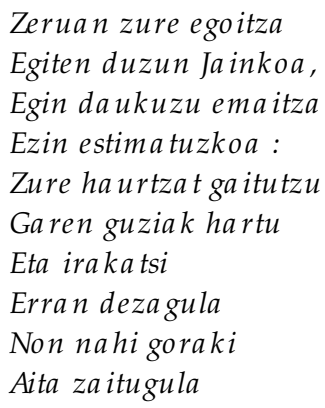

Bigarren kantua oso bitxia da biltzen baititu lau, bost, sei, zazpi eta zortzi silabako neurtitzak honela antolaturik (6-7-7-8-6-4-5-4-5-8). "Munduko gauzen ez deustasuna"-ren adiarazteko hautatu du frantses aire bat "Tout n'est que vanité" gaiari doakoan errimak banatzen direla ( $\mathrm{a} a \mathrm{~b}$ b c b c b d d), bi aldiz parekatuak gero gurutzatuak eta azkenik parekatuak.

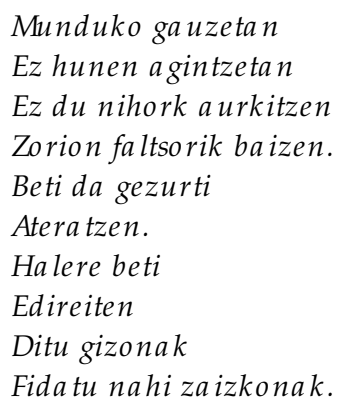

Argi eta garbi dago errima hanitz behar zituela Salvat Monho-k laukoetan ere bat baino gehiago baliatzen baitzuen. Eta ikusi dugun bezala are gehiago seitik hamarrera doazen kantuetan. Halere ez dirudi errima arraroen bila joan dela.

Lafitte-k jujatu du olerkaria :

"Cependant Monho est loin des complications de certains versificateurs scrupuleux; il ne recherche pas la rime riche, il ne craint pas les hiatus, il ne pratique systématiquement ni l'élision ni la synérèse. Il use, selon les besoins, de formes contractes et de formes complètes."

Errimari dagokionez eta Lafitte-k aipatzen dituen bertze gaietan berdin, Salvat Monho jokatzen da bertsulariak bezala.

1) Anitzetan aski zaio asonantzia, bokal batekin bakarrik, hala nola ibili/hasi, dabiltza/tringilka, duela/inporta eta abar... dakielarik ere bokalaren ondotik datorren kontsonantea balio gabekoa dela eta beraz $u$ asonantziarekin doaz glub batzuk eta $e$ asonantziarekin Josep/kristauek. 
2) Ontzat hartzen du bertsulariek bezala kontsonanteen arteko kidetasuna.

$\begin{array}{lll}\text { - leherkarietan } & \mathrm{k} / \mathrm{naiteke/naute} \\ \mathrm{k} / \mathrm{g} & \begin{array}{l}\text { barroki/ongi } \\ \text { sortu/du } \\ \text { exatu/hastandu } \\ \text { berri/aintzindari } \\ \text { ama/birjina } \\ \text { - dardarkarietan }\end{array} & \mathrm{rr} / \mathrm{r} \text { /garbiena } \\ \text { - sudurkarietan } & \mathrm{m} / \mathrm{n} & \begin{array}{l}\text { ona/arima } \\ \text { geroz/glorios } \\ \text { galarazi/irakatsi }\end{array} \\ \text { - txistukariekin } & \mathrm{n} / \mathrm{m} / \mathrm{s}\end{array}$

Aise erabiltzen ditu errima gramatikalak bai aditzekin : ikusi/nahasi, segitzen/pentsatzen, utziko/ahantziko, limatu/hedatu, bai atzizkiekin : oilaskotaraino/elizaraino, Bardoztarrek/Jainkotiarrek, zintzurrak/bazterrak, bidean/aldean, aintzinetik/katiximatik eta bertze..., bainan ahal hori emaiten dio hizkuntzak.

Orotara, Monho kantu egilearen baitan datza bi ohidura. Lehena, aspalditik datorrena bertsulariena, lauko neurtitz luzedunak baliatuz bereziki lauko ertaina $(8+7)$, eta lauko ttipia $(7+6)$, bainan denbora berean XVII. mendeko olerkarien metrikari jarraikitzen zaio, errima parekatuak erabiliz.

Bigarrena da elizako kantuekin hasi zen bezala, atzerrietako, bereziki Frantziatik jinikako aireak hartuz moldatzen direla kantu berriak erabiltzen direlarik errima parekatuak, gurutzatuak edo besarkatuak. Monho-ri esker badakigu zein diren doñu horiek, bi bederen kantu latinetarik hartuak, gehienak, dirudienez, frantses kantutegietarik. Horretan neurt daiteke frantsesaren eragina, bereziki XVIII. mendean. Badakigu hasia zela XVII.-ean, bainan eragin gehiago ukanen du Ilustrazio garaian eta iraultza denboran, Salvat Monho lekuko. 